\title{
Interactive Game Based Learning: Advantages and Disadvantages
}

\author{
Margit Pohl ${ }^{1}$, Markus Rester ${ }^{1}$, and Peter Judmaier ${ }^{2}$ \\ ${ }^{1}$ Institute of Design and Assessment of Technology, \\ Vienna University of Technology, Favoritenstr. 9-11 / 187, A-1040 Vienna \\ margitaigw.tuwien.ac.at \\ ${ }^{2}$ Institute of Engineering Design and Logistics Engineering, \\ Vienna University of Technology, Getreidemarkt 9/ 307, A-1060 Vienna
}

\begin{abstract}
Interactive Game-Based Learning might be used to raise the awareness of students concerning questions of sustainability. Sustainability is a very complex topic. By interacting with a simulation game, students can get a more detailed and holistic conception of how sustainability can be achieved in everyday purchasing situations. The SuLi (Sustainable Living) game was developed to achieve this goal. In an evaluation study we found evidence that SuLi is an interesting alternative to more traditional approaches to learning. Nevertheless, there are still many open questions, as, e.g., whether one should combine simulation games with other forms of teaching and learning or how to design simulation games so that students really acquire detailed concepts of the domain.
\end{abstract}

Keywords: Game Based Learning, Evaluation, Ecodesign, Life Cycle Thinking.

\section{Introduction}

Raising public awareness about questions of sustainability is getting more and more important. The discussion of such questions should probably start at an early age. Introducing this topic in school education seems to be necessary. The SuLi (Sustainable Living) game aims at transferring basic knowledge about sustainability to young people starting from the age of 14 years onward. Informed consumers can influence product design of consumer goods by either buying sustainable products or not. Unluckily, most people are not able to make such informed decisions. The global dimensions of production processes leads to a complexity hardly conceivable for customers. Usually, the price, the functionality, the design and the image of a product are the main reasons for consumers to buy a product. Sustainability seldom is a criterion. The aim of the SuLi game is to raise the awareness of teenagers to consider such issues in their purchasing behavior.

In this context, the concept of Life Cycle Thinking which reflects the ecological impact of a product along its whole life cycle (raw material, manufacturing, distribution, use, end of life/recycling) is essential. Sustainable product design is a complex domain, and it is not a trivial task to represent the interdependencies between different factors influencing it. We think that a simulation game might be a possibility to 
convey such information. Tennyson and Jorczak [18] argue that "simulation games offer the highest potential as instructional games" because they motivate students to apply real-world behavior. Similar to the real world, students interact with the game in an iterative manner and change the state of the simulation to reach a desired goal.

The following paper describes the concept of the SuLi game and an evaluation study using focus groups to assess whether the teenagers reflect about issues of sustainability when they play this game.

\section{Description of the Game}

\subsection{The SuLi World}

In the SuLi game, the players' task is to produce goods of daily life and then to consume them, which means that in most cases they have to buy products from each other. An important feature of the game is that every players' actions influence the other players' situation. The game is based on a concept of rounds. In every round, players decide which goods to produce, where to produce them, which raw materials are used, what means of transportation are adopted and what the price of the good should be. The state of the SuLi universe (see Fig. 1) is, therefore, a result of all players' activities.

Every player gets an avatar who is living on his or her own island (see Fig. 2). These islands are characterized by a different supply of raw materials, social standards and ecological and economic conditions. The players have to make decisions about how to produce goods - whether to produce them in a more sustainable manner

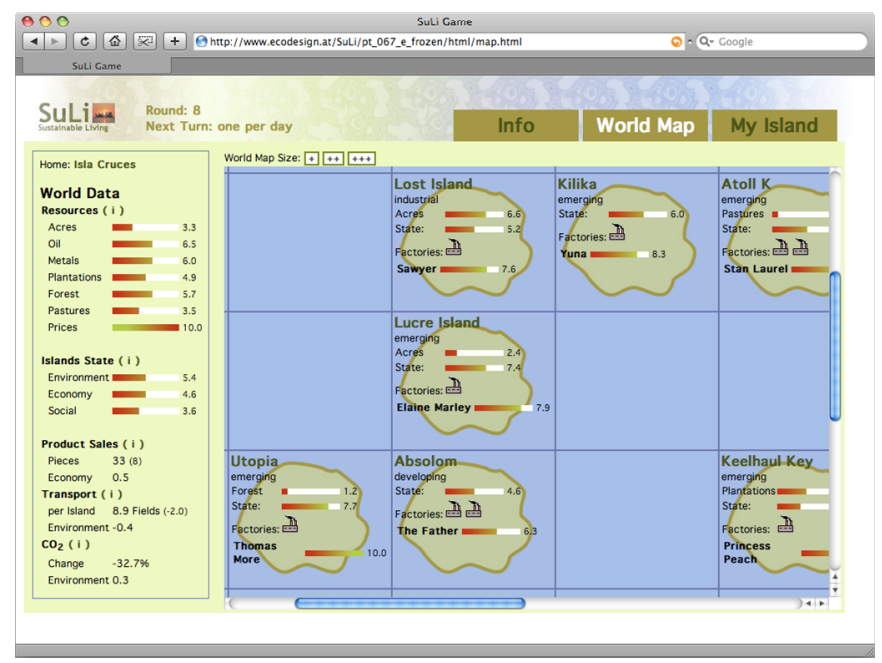

Fig. 1. The SuLi universe: map of islands and data about the state of the SuLi universe (raw materials, ecology, economy, social situation) 


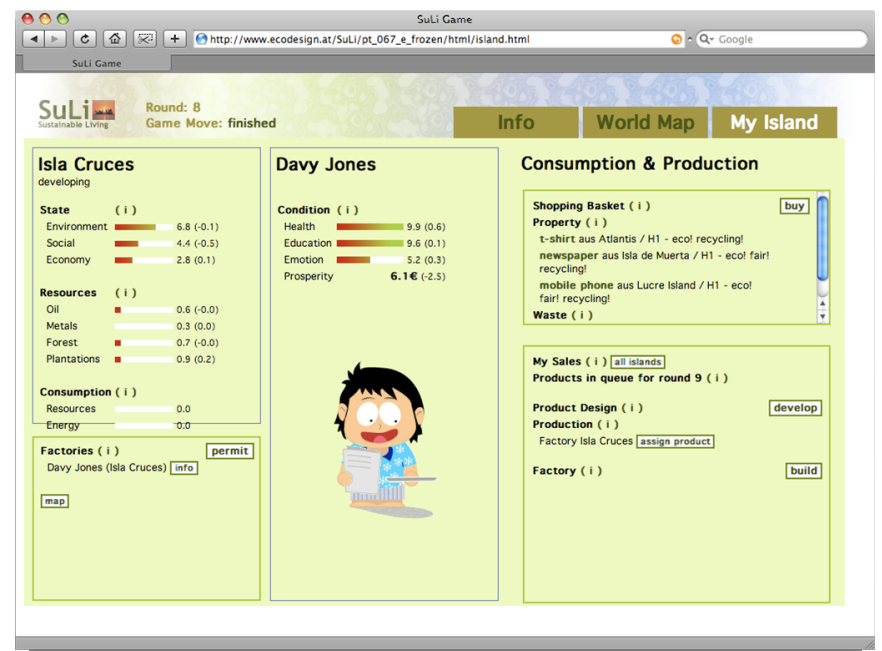

Fig. 2. View of the home island: details on island (ecological, social, and economic situation), avatar (health, wealth, education, and mental balance), consumption (marketplace, inventory, and waste), and production (developed products and actual production)

(which implies that, e.g. these goods become more expensive but also more durable) or not (which leads to, e.g., the pollution of the island and, as a consequence, deteriorates the health of the avatar). The overall situation on each players' island is reflected also by the appearance of the avatar. For instance all purchased items are visualized by the avatar (see Fig. 3). The avatar not only needs food and clothing but also means for communication and recreation to increase his or her well-being. If, for instance, a player does not purchase food in a round, the avatar gets sick. After another round without eating or drinking the avatar "dies".

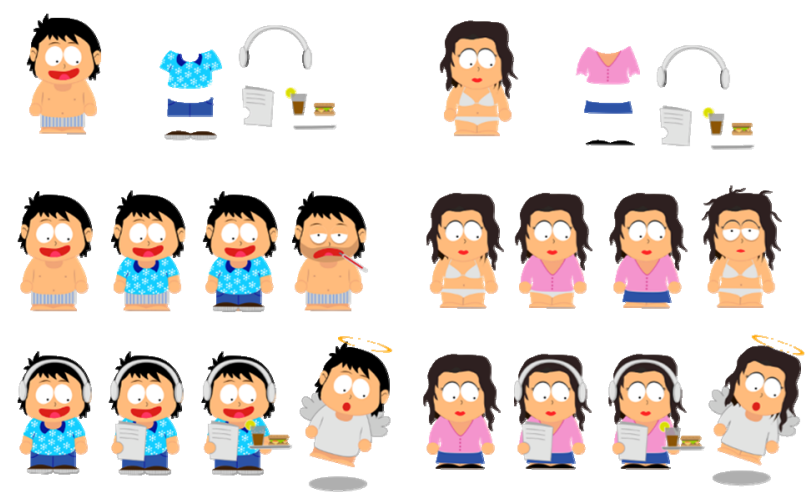

Fig. 3. The avatar visualizes not only the health and emotional situation but also all purchased items 
The game also includes a chat facility and a discussion forum enabling the players to communicate with each other during the play (e.g., to develop common strategies or to inform each other about the state of the game).

The target group of the game is secondary schools students, but we think that the game could also be used for beginners at universities.

\subsection{Participatory Iterative Design and Evaluation}

A participatory development process with the active involvement of pupils was implemented. This process is divided into three phases (cf. [15]):

1. The first phase was intended to review the basic game idea and the establishment of relevant factors in the target group for the concept of Life Cycle Thinking. These factors formed the basis for the simulation model. In a first gameplay a paper based prototype was tested. The outcome was a game concept with the most important factors of the simulation model and rules for the interaction process.

2. The second phase was the development of an executable prototype. Interested pupils (the so-called core group) aided in the search for and elaboration of data for the chosen products. They also acted as consultants in the implementation of the game prototype. By this means these pupils also got insight into scientific work practice.

3. In the last phase, a test run of the prototype took place in the courses of an enlarged group of pupils. Beside the core group many other pupils participated, who were not involved in the development process. The pupils from the development team acted also as supportive tutors during this test phase.

\section{Related Work}

Game-Based learning has become increasingly popular in recent years. Nevertheless, many authors point out that there is still too little systematic and conclusive research in this area [1]. One of the positive effects described most often is increasing motivation [16], [6]. Tennyson \& Jorczak [18] argue that both cognitive and affective variables are essential for playing games successfully. Simulations engage users because of their similarity to complex real-world situations [8]. Pagulayan et al. [14] also indicate that interactivity is not enough to make games motivating. Games also need a convincing story line.

Recently, the potential of game-based learning for supporting collaborative learning has been increasingly discussed, especially because of the widespread use of Massively Multiplayer Online Games (see, e.g., [17]). There is some evidence that games can support team work and collaboration between learners although it is necessary to look into this in greater detail. Duchenaut et al. [4] argue that many players (especially players at lower levels of such games) in MMOGs play alone, not in groups. Collaborative playing is usually adopted when goals can only be achieved by a group. Groups often face difficulties in cooperation because of the different time-constraints of the various players. This makes groups or guilds in MMOGs very fragile [5]. Relationships between people communicating via the Internet are often described as weak and shallow. Nardi and Harris [13] point out that such relationships may be an asset instead of a disadvantage. Weak relationship may make learning in MMOGs more fun 
and enable learners to be more flexible. All this indicates that communication and cooperation have to be designed carefully so that they can be integrated usefully into the learning process.

In the literature, several difficulties have been described concerning the design of game-based learning [9]. Computer games are usually played because they are fun and not to reach an external goal. In contrast to that, learning usually has an external goal (to learn some topic defined by the teacher). This contradiction is often difficult to overcome. Curtis et al. [3] argue that there might be solutions to this, e.g., by integrating a first person view into the game and giving the players ample possibilities for challenging choices. In the SuLi game, this contradiction was highly obvious. Players could either aim at earning money or at preserving the ecological stability of the SuLi world. To aim at earning money was an individualistic choice which enabled players to improve the situation of their avatar. It conformed to strategies usually adopted in computer games. Improving the ecological stability of the SuLi world as a whole was an altruistic choice often leading to a deterioration of the situation of the avatar. The first strategy was certainly more fun for the players, but it did not generate highly sophisticated insights. Players who adopted this choice usually ignored information given by the system about the state of the island on which their avatar lived or the SuLi world as a whole.

Another problem of game-based learning sometimes mentioned in the literature is that the flow of playing a computer game hinders students to reflect about what they are doing [1]. We also noticed this when we evaluated the SuLi game. Students often only tried to improve their own scores, but avoided looking at the information about the state of the SuLi world. During the focus group which we conducted to analyze the usefulness of the game, we noticed that students (and also the teacher who was present) found the group discussion valuable to get insights they might not have got without this discussion in the class. Such a procedure is also recommended by several authors. Tennyson and Jorczak [18] point out that only few games are designed so that satisfactory learning can happen by just playing the game. Often, explicit learner support is necessary (e.g., tutorials and reference information). Lauer and Leutner [10] also describe several studies indicating that the discovery process in simulations should be carefully guided and that missing information should be provided in a "just-in-time" manner.

Barton and Maharg [2] discuss the problem of the representation of reality in educational simulations. They argue that it is an open question whether to represent reality "as it is" or to emphasize certain aspects of reality for the educational purposes. In the SuLi development group, we discussed extensively whether ecologically sound behavior of the players should be rewarded or not. In reality, such behavior is often "punished". Buying sustainable products is, e.g., much more expensive than buying other products. A game rewarding sustainable behavior would deviate from reality considerably, thereby giving students a "wrong" impression of how our society and economy works. On the other hand, it might be argued that such a concept of the game would emphasize the aspect of sustainability and thereby raise students awareness better than a realistic simulation could do. In the end, we decided to develop a "realistic" game reflecting existing circumstances in society.

The related work discussed above formed a valuable input for the formulation of our categories of analysis described in the next section. 


\section{Data Acquisition and Methodology}

Lai-Chong Law et al. [12] argue that it is necessary to test educational games with real users. The success of an educational game is, to a large extent, based on what is called User Experience (see, e.g., [7]). This is a variable which can only be measured in interaction with real users. Approaches like heuristic evaluation are not appropriate in this context. Lai-Chong Law et al. [12] also point out that mixed-method evaluation is advisable because of the possibility of triangulation of multi-source data. Barton and Maharg [2] posit that discovery learning should not only be studied in the laboratory, but also "in the wild". In that way, many of the complex factors influencing learners' behavior and attitudes can be considered which is not possible in rigidly designed laboratory studies. Among other methods, Barton and Maharg use focus groups (see, e.g., [11]) as methodology.

Focus groups are a convenient method to assess software and educational programs. They enable researchers to get a quick and comprehensive overview about the attitudes of potential users and of possible drawbacks of the system under development. One of the main advantages of focus groups is that participants can clarify controversial issues in the discussion. A disadvantage of focus groups is that in the discussion, not all the participants take part evenly. Some participants will talk more and influence the opinion of the group more than others. Therefore, it is advantageous to combine focus groups with other methodologies. Usually, focus groups are moderated by a facilitator based on a framework of questions.

The research reported in the next section is based on a focus group conducted in a Viennese secondary school. 18 students participated in the discussion. About half of them were female. The duration of the focus group was approximately one hour. The discussion was recorded and then the main points were transcribed. The aim of the study was to find out whether the SuLi game can be integrated into secondary education easily, is motivating and understandable and raises the awareness of the students for questions of sustainability. These questions could only be investigated in a realistic setting, that is, in a school. Despite the organizational problems, we decided to use pupils from a secondary school as subjects for the evaluation.

The framework of questions was based on the literature study described in section 3. The following topics were addressed in the discussion:

- Strategy Adopted: This question is specific for the SuLi game. We wanted to know whether students rather adopted an individualistic or a sustainable strategy and what reasons they had for this choice.

- Communication and Collaboration: Communication and collaboration is an important issue in online games and is seen as one of the strengths of this approach. We wanted to find out how much students communicated and cooperated with each other.

- Game vs. Learning Program: As mentioned above, there is often a contradiction between the game aspects and the learning aspects of an educational game. We wanted to find out whether students realize this contradiction and if they think that the $\mathrm{SuLi}$ is more a game or a learning program. 
- Complexity: The right complexity is essential for the success of an educational game [1]. We wanted to find out whether students thought that SuLi was too difficult or too easy.

- Transparency of the Simulation; Relationship to the Real World: As described above, it sometimes is an open question whether educational simulation games should represent the world "as it is" or should emphasize some aspects to reach an educational goal. We wanted to find out whether students found the simulation understandable and transparent, and whether it was realistic.

- Improvements: We wanted to gather suggestions for potential improvements for the SuLi game from the students.

We also used other methodologies in the SuLi project, especially diaries which students wrote while working with the SuLi game and logfiles of the students' actions while playing the game. The results of these studies will be described elsewhere.

\section{Results}

In the following section, we will describe the results from the focus group.

The results concerning the strategy the students chose were very interesting. We did not get answers from all students, but from a fairly big sample. The strategies were very diverse. Several said that, at least at the beginning, they only wanted to earn money. Some of those changed their strategies in the middle of the game when they realized that increasing pollution made their avatar sick. The general opinion which emerged during the focus group discussion was that it was impossible to produce in a sustainable manner and to make a large profit at the same time. We got the impression that this insight also was a result of the controversial discussion in the classroom, not only of the students playing the game. Only few students followed a sustainable strategy from the beginning.

The students also communicated with each other during the game. They predominantly helped each other on how the game worked. Partly, they used the chat functionality integrated into the game, but unluckily this functionality had a few usability problems, therefore, a few used email or other forms of communication. Some of them tried to cooperate in small groups to achieve better results (e.g., by only buying the products of the other group members). One group succeeded in this, another failed.

We asked the students whether the game was exciting or boring and whether it was more a game or more a learning program. Students found the game quite interesting, especially because there were many players in the game. But their impression was predominantly that of an educational program. Interestingly, many of them mentioned that the lack of the possibility to improve sustainability and profit at the same time made SuLi so complex that it rather was a learning program, not a game.

We also asked whether the SuLi game was too easy or too difficult to understand and to play. Six of the students said that it was quite simple, eight argued that it was difficult in the beginning but easier in the end when one had got used to it. Three students thought that the game was quite difficult. Students argued that it was difficult to keep track of all the variables (especially for the state of the SuLi world). When students try to derive information about how different variables relate to each other 
(e.g., materials used, forms of transport used, $\mathrm{CO}_{2}$ level in the SuLi world, etc.) the game seems to be quite complex.

When we asked whether students rather considered the state of their own avatar, their island or the state of the SuLi world, we got quite contradictory answers. Two remarked that they tried to produce in a sustainable way, the others said that they did not care about the environment in the SuLi world. One of the students said that he/she did not care about $\mathrm{CO}_{2}$ because these values did not directly affect the state of his/her own avatar. Another student remarked that this was just a game, so he/she did not care about the environment. In reality, he/she would be much more considerate.

The SuLi game is based on a very complex algorithm on how the economy and the ecology of the SuLi world develops. Students generally found these relationships not very transparent. On the other hand, they argued that this is very realistic as this is also the case in real life. To a certain extent, they found the game realistic, but they also emphasized several differences (e.g., that in the game everyone has the same possibilities at the beginning of the game which is not the case in the real world). Concerning these questions, the students also discussed issues not contained in the framework of questions used to moderate this focus group. They especially discussed how the state of the SuLi world could have been improved, e.g., by using ships instead of airplanes as means of transportation. One member of the development group mentioned in the discussion that the state of the ecology of the SuLi world was quite bad after the 6th round of the game. Most of the students apparently were not aware of this fact. Students also discussed what it means to win in the SuLi game. This is not a trivial question. One student said, that winning was to be better than the other students, which would be the logic of traditional computer games. The predominant opinion was that winning meant to have money left in the last round and losing meant that one's avatar "died". A minority opinion was that having good values for all variables (in the economy, ecology and the social situation) implied that a player had won the game.

The students also made several suggestions as to how to improve the game. They argued that more products and more resources might make the game more interesting because then the game could be played for longer periods of time. Also, the prices should be more realistic. In the game, a mobile phone is less expensive than a hamburger - this should not be possible.

In general, the focus group discussion was extremely interesting. We got the impression (which was corroborated by the teacher who was present) that the students got relevant insights through the discussion. In a way, playing the game was a starting point for the discussion because it offered students systematic personal experience about the topic at hand. Students sometimes formulated quite sophisticated insights about the relation between reality and the game universe. In a computer game, they apparently sometimes act out behavior they would not adopt in real life (e.g., being glad that a competing student "died" during the game). Nevertheless, they also got interesting insights through the game.

\section{Conclusion}

Our results indicate that the SuLi game can be used in secondary education and that students feel motivated to work with this program and enjoy to play with it. Nevertheless, there are still open questions concerning this game where further research is 
necessary. The results of the focus group also indicate that it would be advisable to use the SuLi game in conjunction with other forms of teaching (e.g., group discussions like the focus group). Another problem of the SuLi game is that students usually do not heed the more general information about the economic, ecological and social state of the SuLi world offered by the system. There are several possible reasons for this. On the one hand, it is possible to play the game without looking at these variables. A solution for this might be a redesign of the game in a way that forces players to look at these values. Another possible solution also might be a more appropriate representation of this information and better feedback about the state of the SuLi world to the students. Communication and cooperation among students could also be reinforced by a careful design of the program. In these areas, more research is necessary.

In the near future, we will also analyze the diaries and the software logs to get more information about how students interacted with the SuLi game. We will then compare this information to the results reported above to get a detailed and valid account of the usefulness of the SuLi game.

Acknowledgments. The project "Konzeption eines ECODESIGN Lernspiels für Schulen und Jugendorganisationen" was financed by the Federal Ministry of Transport, Innovation and Technology (BMVIT) and Österreichische Forschungsförderungsgesellschaft (FFG) (Grant 813029).

\section{References}

1. Akilli, G.K.: Games and Simulations: A New Approach in Education. In: Games and Simulations in Online Learning, pp. 1-20. Information Society Publishing, Hershey (2007)

2. Barton, K., Maharg, P.: E-Simulations in the Wild: Interdisciplinary Research, Desing and Implementation. In: Games and Simulations in Online Learning, pp. 115-148. Information Society Publishing, Hershey (2007)

3. Curtis, M.T., Harper-Sciarini, M., DiazGranados, D., Salas, E., Jentsch, F.: Utilizing Multiplayer Games for Team Training: Some Guidelines. In: Computer Games and Team and Individual Learning, pp. 145-165. Elsevier, Amsterdam (2008)

4. Ducheneaut, N., Yee, N., Nickell, E., Moore, R.J.: Alone Together? Exploring the Social Dynamics of Massively Multiplayer Online Games. In: Proc. of CHI 2006, pp. 407-416 (2006)

5. Ducheneaut, N., Yee, N., Nickell, E., Moore, R.J.: The Life and Death of Online Gaming Communities: A Look at Guilds in World of Warcraft. In: Proceedings of the CHI 2007 conference, pp. 839-848 (2007)

6. Ebner, M., Holzinger, A.: Successful Implementation of User-Centered Game Based Learning in Higher Education - an Example from Civil Engineering. Computers \& Education 49(3), 873-890 (2007)

7. Hassenzahl, M., Tractinsky, N.: User Experience - a research agenda. Behavior \& Information Technology 25(2), 91-97 (2006)

8. Holzinger, A., Kickmeier-Rust, M., Wassertheurer, S., Hessinger, M.: Learning Performance with Interactive Simulations in Medical education: Lessons learned from results of learning complex physiological models with the HAEMOdynamics SIMulator. Computers \& Education 52(1), 292-301 (2009) 
9. Kickmeier-Rust, M.D., Schwarz, D., Albert, D., Verpoorten, D., Castaigne, J.-L., Bopp, M.: The Elektra Project: Towards a New Learning Experience. In: M3-Interdisciplinary Aspects on Digital Media \& Education, pp. 19-48. Austrian Computer Society (2006)

10. Klauer, K.J., Leutner, D.: Lehren und Lernen. Einführung in die Instruktionspsychologie. Beltz, Weinheim (2007)

11. Kuniavsky, M.: User Experience: A Practitioner's Guide for User Research. Morgan Kaufmann, San Francisco (2003)

12. Lai-Chong Law, E., Kickmeier-Rust, M.D., Albert, D., Holzinger, A.: Challenges in the Development and Evaluation of Immersive Digital Educational Games. In: HCI and Usability for Education and Work, pp. 19-30. Austrian Computer Society (2008)

13. Nardi, B., Harris, J.: Strangers and Friends: Collaborative Play in World of Warcraft. In: Proceedings of the CSCW 2006 conference, pp. 149-158 (2006)

14. Pagulayan, R.J., Keeker, K., Wixon, D., Romero, R.L., Fuller, T.: User-Centered Design n Games. In: Jacko, J.A., Sears, A. (eds.) The Human-Comuter Interaction Handbook, pp. 883-906. Lawrence Erlbaum, Mahwah (2003)

15. Pohl, M., Rester, M., Judmaier, P., Leopold, D.: Designing game based learning - a participatory approach. In: Proc. of ED-MEDIA 2008, pp. 1317-1322. Association for the Advancement of Computing in Education, Chesapeake (2008)

16. Prensky, M.: Digital Game-Based Learning. Paragon House, St. Paul (2001)

17. Steinkuehler, C.A.: Learning in Massively Multiplayer Online Games. In: Proc. of the 6th Intl. Conf. on Learning Sciences ICLS 2004, pp. 521-528 (2004)

18. Tennyson, R.D., Jorczak, R.L.: A Conceptual Framework for the Empirical Study of Instructional Games. In: Computer Games and Team and Individual Learning, pp. 3-20. Elsevier, Amsterdam (2008) 